\title{
GP-confirmed complete Achilles tendon rupture using pocket-sized ultrasound: a case report
}

\author{
SJ Davis, MBChB ${ }^{1 *}$, A Lott, MBBS ${ }^{2}$, E Besada, MD³
}

${ }^{1}$ GP \& University Lecturer, Department of General Practice, Institute of Community Medicine, University of Troms $\varnothing$, Tromsø, Norway; ${ }^{2}$ Junior Radiologist, Department of Radiology, Institute of Clinical Medicine, University of Tromsø (UiT) The Arctic University of Norway, Tromsø, Norway; ${ }^{3}$ Rheumatologist \& University Lecturer, Department of Rheumatology, Institute of Clinical Medicine, University of Tromsø (UiT) The Arctic University of Norway, Tromsø, Norway

\section{Introduction}

The incidence of complete Achilles tendon rupture is 18 per 100000 patient-years ${ }^{1}$ and is usually diagnosed clinically by GPs. The extent of clinical misdiagnosis is unknown in Norway, but may be high. $^{2}$ This is important as delayed treatment has unfavourable consequences. ${ }^{1,3}$ We report how a GP, with no clinical ultrasound experience, recorded images with a pocket-sized ultrasound device (PSUD) under supervision to confirm a complete Achilles tendon rupture. This could present a new indication for GP ultrasound.

\section{Case report}

A 36-year-old man experienced acute pain above the right heel accompanied by an audible snap while sprinting. He immediately had difficulty walking and 3 hours later consulted an on-call GP. Posterior ankle swelling with a tender depression $3 \mathrm{~cm}$ proximal to the calcaneum was found. Active plantar flexion against resistance was weak and Simmonds-Thompson test was 'partially positive' on applying a strong calf-squeeze. Based on these findings, calf muscle rupture was diagnosed as the Achilles tendon was thought to be intact. The patient was advised to elevate the foot and wait 2

*For correspondence: sdnibley@ gmail.com

Competing interests: The authors declare that no competing interests exist.

Received: 25 November 2016 Accepted: 08 December 2016 Published: 26 July 2017

(c) This article is Open Access: CC BY license (https://

creativecommons.org/licenses/ by/4.0/)

Author Keywords: ultrasound, general practitioner, GP, pocket, tendon

Copyright (C) The Authors 2017; DOI:10.3399/

bjgpopen17X100893 weeks for improvement. Two days later a second GP, who was aware of a history of an audible snap, considered complete tendon rupture and reexamined the patient. Findings included an absent right heel raise due to weakness, minimal active plantar flexion against gravity and lying prone, significant right ankle swelling without bruising, and an altered angle of declination. Palpation elicited no ankle bony tenderness, yet a painful gap was identified $6 \mathrm{~cm}$ proximal from the calcaneal attachment, along the line of the Achilles tendon. Simmonds-Thompson's test was clearly positive. The positive Simmond's triad indicated a clinical diagnosis of complete rupture of the Achilles tendon.

A 3.4-8 MHz linear array probe PSUD (VScan ${ }^{\mathrm{TM}}$ dual probe, GE Healthcare), set at a depth of $3.5 \mathrm{~cm}$, was used under the supervision of a rheumatologist experienced in ultrasound. The tendon was enlarged from $1 \mathrm{~cm}$ to $6 \mathrm{~cm}$ above the calcaneal insertion, where a clear gap was seen (Figure 1). Two hours later a radiologist-performed ultrasound (LOGIQ E9TM, GE Healthcare) and reported an enlarged distal tendon and a complete rupture at 5-6 cm from the calcaneal attachment, creating a $2.7 \mathrm{~cm}$ blood-filled gap (Figure 2). Surgical exploration 8 days post-injury found a complete Achilles tendon rupture '5-10 cm above the ankle joint'.

\section{Discussion}

Tromsø Hospital serves a large area with a population of approximately 160000 . Between 20102014 an average of 21 patients per year were referred by their GP for suspected Achilles rupture. 


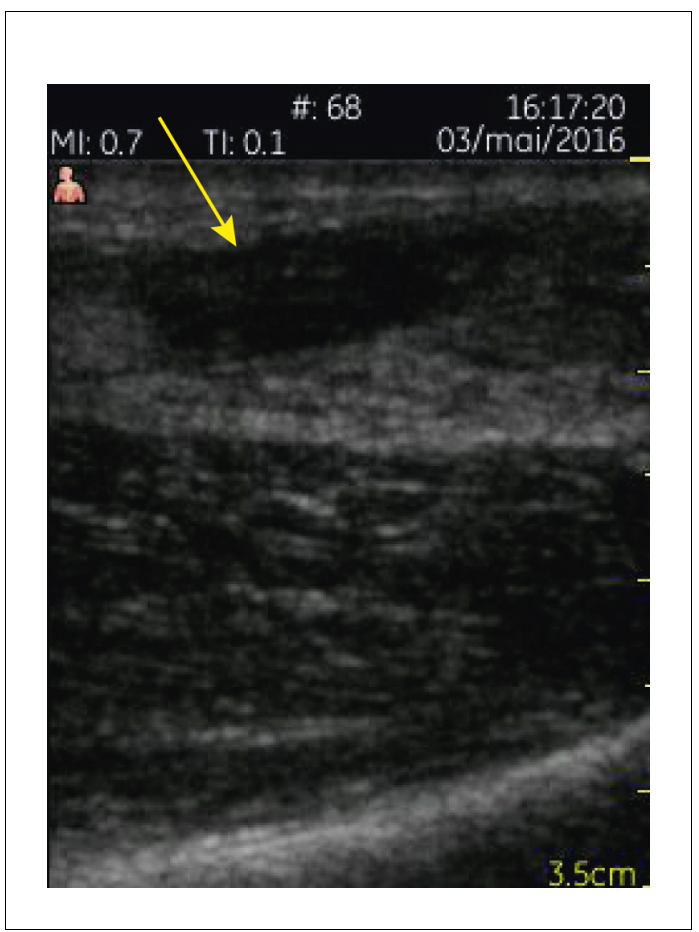

Figure 1. Pocket-sized ultrasound sagittal view of the Achilles rupture.

( $100 \%, 6,7$ The value for PSUDs is unknown and pO for diagnosing complete Achilles ruptures of $100 \%{ }^{6,7}$ The value for PSUDs is unknown and possibly lower due to poorer imaging and operator technique and/or interpretation. The VScan did however answer the clinical question about complete rupture. Research should compare both devices on a larger scale for complete rupture and alternative pathologies, such as partial rupture.

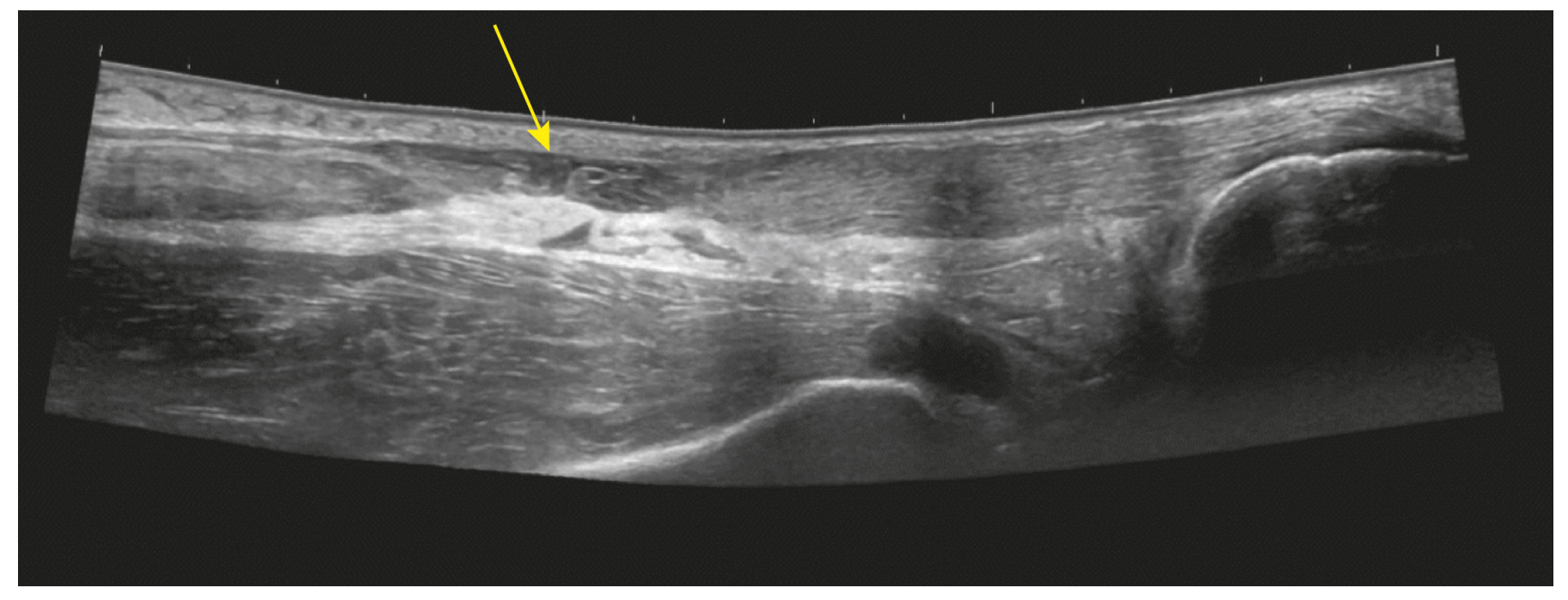

Figure 2. Hospital ultrasound sagittal view of the Achilles rupture. 
Norwegian GPs already use ultrasound to assess urinary retention, fetal viability, deep venous thrombosis, gall stones, abdominal aortic aneurysm, and skin abscesses. These indications still apply despite no requirement for certified training in Norway. The evidence base for diagnostic accuracy and impact on clinical outcomes is weak, ${ }^{8,9}$ yet this should not deter primary care research. This new indication for PSUDs has already benefitted emergency medicine ${ }^{10}$ and could also save orthopaedic consultation time. The role of GP ultrasound should be to reduce misdiagnosis and provide a safer opportunity to develop generic ultrasound skills. We hope this report will stimulate research collaboration to assess the impact of GP ultrasound on measurable clinical end-points related to Achilles tendon injury.

Provenance

Freely submitted; externally peer reviewed.

Patient consent

The patient consented to the publication of this article and the associated images.

\section{References}

1. Leppilahti J, Puranen J, Orava S. Incidence of Achilles tendon rupture. Acta Orthop Scand 1996; 67(3): 277279. doi: $10.3109 / 17453679608994688$

2. Inglis $A E$, Scott $W N$, Sculco TP, et al. Ruptures of the tendo achillis. An objective assessment of surgical and non-surgical treatment. J Bone Joint Surg 1976; 58(7): 990-993. doi: 10.2106/00004623-197658070-00015

3. Den Hartog BD. Surgical strategies: delayed diagnosis or neglected achilles' tendon ruptures. Foot \& Ankle Int 2008; 29(4): 456-463. doi: 10.3113/FAl.2008.0456

4. Singh D. Acute Achilles tendon rupture. BMJ 2015; 351:h4722. doi: 10.1136/bmj.h4722

5. Gravlee JR, Hatch RL, Galea AM. Achilles tendon rupture: a challenging diagnosis. J Am Board Fam Prac 2000; 13(5): 371-373.

6. Gulati V, Jaggard M, Al-Nammari SS, et al. Management of achilles tendon injury: A current concepts systematic review. World J Orthop 2015; 6(4): 380-386. doi: 10.5312/wjo.v6.i4.380

7. Hartgerink P, Fessell DP, Jacobson JA, et al. Full- versus partial-thickness Achilles tendon tears: sonographic accuracy and characterization in 26 cases with surgical correlation. Radiology 2001; 220(2): 406-412. doi: 10. 1148/radiology.220.2.r01au41406

8. Lærum F, Eik-Nes S, Fønnebø V, et al. Diagnostikk med ultralyd i primærhelsetjesten. http://www. kunnskapssenteret.no/publikasjoner/_attachment/172407?_ts=14855a790e3 (accessed 10 Jul 2017)

9. Wordsworth S, Scott A. Ultrasound scanning by general practitioners: is it worthwhile? J Pub Heal 2002; 24 (2): 88-94. doi: 10.1093/pubmed/24.2.88

10. Stickles SP, Friedman L, Demarest M, et al. Achilles tendon rupture. Western J Emer Med 2015; 16(1): $161-$ 162. doi: 10.5811/westjem.2014.10.24127 